\title{
Spectrophotometric determination of iron and boron in soil extracts using a multi-syringe flow injection system
}

\author{
D.M.C. Gomes ${ }^{\mathrm{a}}$, M.A. Segundo ${ }^{\mathrm{a}, *}$, J.L.F.C. Lima ${ }^{\mathrm{a}}$, A.O.S.S. Rangel ${ }^{\mathrm{b}}$ \\ a REQUIMTE, Serviço de Química-Física, Faculdade de Farmácia, Universidade do Porto, Rua Aníbal Cunha 164, 4050-047 Porto, Portugal \\ ${ }^{\mathrm{b}}$ Escola Superior de Biotecnologia, Universidade Católica Portuguesa, Rua Dr. António Bernardino de Almeida, 4200-072 Porto, Portugal
}

Keywords: Multi-syringe; Boron; Iron; Soil extracts; Spectrophotometry; Flow injection

\begin{abstract}
In the last decade, significant advances in flow analysis have been reported, namely the extensive use of computer-controlled devices to enhance the autonomy and performance of analysers. In the present work, computer-controlled multi-syringe flow injection systems are proposed to perform the spectrophotometric determination of available iron and boron in soil extracts. The methodologies were based on the formation of ferroin complex (determination of iron) and azomethine-H reaction (determination of boron). Both determinations were performed in manifolds with similar configurations by changing the reagents present in the different syringes. In the determination of iron, elimination of Schlieren effect in the detection system was achieved through the binary sampling approach, where a three-way valve was actuated to intercalate small slugs of sample and reagent, promoting better mixing conditions for solutions with different values of refractive index. In the determination of boron, in-line sample blank measurement was attained by omitting the introduction of reagent through software control, without manifold reconfiguration. Linear calibration curves were established between 0.50 and $10.0 \mathrm{mg} \mathrm{Fe} 1^{-1}$ and between 0.20 and $4.0 \mathrm{mg} \mathrm{B}^{-1}$. No systematic difference was found when soil extracts were analysed by the proposed methodologies and compared to the respective reference procedures.
\end{abstract}

\section{Introduction}

Since its introduction in 1975, flow injection analysis [1] (FIA) has been a powerful technique in analytical chemistry. First considered as an appropriate tool to replace segmented flow analysis [2] for automation of chemical analysis, the FIA concept has allowed implementation of procedures that used to be difficult or even not feasible by conventional approaches. These features were provided by the strict control of reaction conditions in both space and time, enabling assays of constituents based on transient components or the use of detection principles relying on transient effects such as chemi and bioluminescence [3,4].

\footnotetext{
* Corresponding author. Tel.: +35122 2078994; fax: +35122 2004427.

E-mail address: msegundo@mail.ff.up.pt (M.A. Segundo).
}

Based on the same principles of FIA, sequential injection analysis (SIA) was proposed in 1990 as a single pump, single valve, and single channel technique [5]. This configuration provided a feasible and mechanically simpler alternative to FIA, announced as the second coming of flow-injection analysis [6]. Recently, the third generation of flow injection analysis was presented as the lab-on-valve format [7], where downscaling to 'nanolitre' operation is attained, while maintaining relatively large bore conduits that minimise surface contamination and clogging [8].

The implementation of FIA was accompanied by the evolution of the commutation concept in order to provide more flexible and versatile flow systems [9], which culminated in the introduction of multi-commutation in 1994 [10]. Use of these systems enables the combination of solutions and analytical paths within the flow network, and allows the imple- 
mentation of segmented, unsegmented or monosegmented flow management [11].

In this context, flow systems based on multi-syringe (MSFIA) were introduced in 1999 [12], aiming the development of robust flow analysers, where the multi-channel operation of FIA was associated to the flexibility of multi-commutation. This type of system relies on the multi-syringe apparatus, composed by a multiple channel piston pump, where all pistons are connected to the same bar, driven by a single motor. Moreover, each syringe is equipped with a solenoid commutation valve, allowing access to two different flow paths [13]. Therefore, four different operations are possible for each syringe depending on the direction of displacement of the piston and on the position of the commutation valve. Additional commutation valves can also be connected to the multi-syringe, enabling the establishment of a flexible flow network.

Until the present moment, different detection systems were coupled to the multi-syringe, resorting to UV-vis spectrophotometry, spectrofluorimetry, atomic fluorescence spectrometry, chemiluminescence and potentiometry. Several applications have been described for determination in different sample matrices, such as natural, tap and waste waters, plants, fertilizers, metallurgical solutions, wines and soft drinks [14].

In the present work the application of multi-syringe flow system to soil analysis is aimed under the auspices of a Portuguese Project funded by the Ministry of Agriculture for implementation of fast and reliable analytical methodologies for soil monitoring. Therefore, the development of spectrophotometric flow methodologies for determination of soil micronutrient species ( $\mathrm{Fe}$ and $\mathrm{B}$ in this case) using a similar manifold is described.

\section{Materials and methods}

\section{Reagents and solutions}

Water from MilliQ system (resistivity > $18 \mathrm{M} \Omega \mathrm{cm}$ ) was used for the preparation of all solutions, and all chemicals were analytical reagent grade. For the determination of boron, all solutions were prepared and stored in polyethylene flasks. The solutions were prepared by dissolution or dilution of reagent in water unless stated otherwise.

For the MSFIA determination of iron, the colour reagent consisted of $0.25 \mathrm{gl}^{-1} 1,10$-phenanthroline and $2 \mathrm{moll}^{-1}$ $\mathrm{NaCH}_{3} \mathrm{COO}$ while the reducing reagent was $5 \mathrm{~g}^{-1}$ ascorbic acid in $0.3 \mathrm{~mol}^{-1} \mathrm{HCl}$. The $\mathrm{Fe}(\mathrm{II})$ stock solution containing $500 \mathrm{mg} \mathrm{l}^{-1}$ was prepared from $\mathrm{Fe}\left(\mathrm{NH}_{4}\right)_{2}\left(\mathrm{SO}_{4}\right)_{2} \cdot 6 \mathrm{H}_{2} \mathrm{O}$ and a $50 \mathrm{mg}^{-1} \mathrm{Fe}(\mathrm{II})$ stock solution was prepared by accurate dilution of the previous solution.

The working standards for the flow system were prepared by measuring the appropriate volume of the $50 \mathrm{mg} \mathrm{l}^{-1} \mathrm{Fe}$ (II) stock solution to a $25 \mathrm{ml}$ volumetric flask. After that, $20 \mathrm{ml}$ of a solution containing $0.25 \mathrm{moll}^{-1}$ of $\mathrm{HCl}$ and $5.0 \mathrm{moll}^{-1}$ of
$\mathrm{NaCl}$ were added and the volume was completed with water. For the reference procedure, working standards between 0.4 and $1.6 \mathrm{mg}^{-1}$ were prepared by accurate dilution of $5 \mathrm{mg}^{-1}$ Fe(II) solution.

The Fe(III) stock solution containing $50 \mathrm{mg}^{-1}$ was also prepared by measuring the appropriate volume of $500 \mathrm{mg}^{-1}$ $\mathrm{Fe}$ (II) stock solution, followed by dropwise addition of $0.02 \mathrm{~mol}^{-1}$ potassium permanganate solution until persistent pink colour before dilution to the final volume.

For assessing possible interference from other species, $2.0 \mathrm{mgl}^{-1} \mathrm{Fe}(\mathrm{II})$ standard solutions containing the other species up to $1000 \mathrm{mg} \mathrm{l}^{-1}$ were prepared using solutions obtained from $\mathrm{AlCl}_{3} \cdot 6 \mathrm{H}_{2} \mathrm{O}, \mathrm{CuCl}_{2} \cdot 2 \mathrm{H}_{2} \mathrm{O}, \mathrm{ZnCl}_{2}, \mathrm{CaCl}_{2} \cdot 2 \mathrm{H}_{2} \mathrm{O}$ and $\mathrm{MnCl}_{2} \cdot 4 \mathrm{H}_{2} \mathrm{O}$. These solutions were prepared by measuring $1 \mathrm{ml}$ of $5 \mathrm{moll}^{-1} \mathrm{HCl}$ solution, $1.00 \mathrm{ml}$ of $50 \mathrm{mg} \mathrm{l}^{-1}$ $\mathrm{Fe}$ (II) stock solution, the appropriate volume of a $2500 \mathrm{mg} \mathrm{l}^{-1}$ of the possible interfering species solution and by adding the appropriate amount of $\mathrm{NaCl}$ to provide a final concentration of $4 \mathrm{~mol}^{-1}$ of $\mathrm{Cl}^{-}$when the volume was completed to $25 \mathrm{ml}$ with water.

For the extraction of available iron from soil, $1 \mathrm{moll}^{-1}$ $\mathrm{NH}_{4} \mathrm{CH}_{3} \mathrm{COO}$ solution ( $\mathrm{pH} 3$ ) and aqua regia were prepared. For the reference procedure, a $15 \mathrm{gl}^{-1} 1,10$-phenanthroline solution was prepared by dissolving $1.5 \mathrm{~g}$ of this reagent in $100 \mathrm{ml}$ of ethanol. A $100 \mathrm{~g} \mathrm{l}^{-1}$ hydroxylamine hydrochloride solution was also prepared.

For the MSFIA determination of boron, the colour reagent was prepared by dissolving $0.42 \mathrm{~g}$ of azomethine- $\mathrm{H}$ in $20 \mathrm{ml}$ of a $20 \mathrm{~g} \mathrm{l}^{-1}$ ascorbic acid solution. The ascorbic acid solution was also used as carrier solution in the flow system. The buffer reagent was prepared by dissolving $39 \mathrm{~g}$ of $\left(\mathrm{NH}_{4}\right)_{2} \mathrm{HPO}_{4}$ and $25 \mathrm{~g}$ of di-sodium-EDTA in $250 \mathrm{ml}$ of water. The $\mathrm{pH}$ of this solution was adjusted by addition of concentrated $\mathrm{HCl}$ or concentrated $\mathrm{NH}_{3}$.

The boron stock solution containing $250 \mathrm{mg} \mathrm{l}^{-1}$ was prepared by dissolving the appropriate amount of $\mathrm{H}_{3} \mathrm{BO}_{3}$ and a $25 \mathrm{mg} \mathrm{B}^{-1}$ stock solution was prepared by accurate dilution of the previous solution. The working standards for the flow system were prepared by accurate dilution of the $25 \mathrm{mg} \mathrm{B}^{-1}$ stock solution.

For assessing possible interference from other species, $1.0 \mathrm{mg} \mathrm{B}^{-1}$ standard solutions containing the other species up to $1000 \mathrm{mg} \mathrm{l}^{-1}$ were prepared using solutions obtained from $\mathrm{AlCl}_{3} \cdot 6 \mathrm{H}_{2} \mathrm{O}, \mathrm{K}_{2} \mathrm{CrO}_{4}, \mathrm{CuCl}_{2} \cdot 2 \mathrm{H}_{2} \mathrm{O}, \mathrm{FeCl}_{3} \cdot 6 \mathrm{H}_{2} \mathrm{O}$ and $\left(\mathrm{NH}_{4}\right)_{6} \mathrm{Mo}_{7} \mathrm{O}_{24} \cdot 4 \mathrm{H}_{2} \mathrm{O}$. These solutions were prepared by measuring $1.00 \mathrm{ml}^{\circ} 25 \mathrm{mg} \mathrm{B} \mathrm{l}^{-1}$ stock solution and the appropriate volume of a $2500 \mathrm{mg} \mathrm{l}^{-1}$ of the other species solution to a $25 \mathrm{ml}$ volumetric flask.

For the boron reference procedure, the azomethine-H solution was prepared by dissolving $0.9 \mathrm{~g}$ of this reagent and $2 \mathrm{~g}$ of ascorbic acid in $10 \mathrm{ml}$ of water with gentle heating in a water bath. When it was dissolved, the volume was completed to $100 \mathrm{ml}$ with water. The buffer masking reagent was prepared by dissolving $250 \mathrm{~g}$ of ammonium acetate and $25 \mathrm{~g}$ of $\mathrm{Na}_{2}$ EDTA in $400 \mathrm{ml}$ of water. After dissolution, $125 \mathrm{ml}$ of concentrated acetic acid were added. 


\section{Apparatus}

Solutions were propelled through the flow system by means of a multi-syringe burette (Crison Instruments, Allela, Spain). This device is a multiple channel piston pump, where all pistons are driven by a single motor, controlled by computer software through a serial port. A three-way commutation valve (NResearch, Caldwell, NJ, USA) was connected to the head of each syringe.

For both applications, the multi-syringe was equipped with four syringes with different volumes: $2.5 \mathrm{ml}$ in positions 1 and $4,5 \mathrm{ml}$ in position 3 and $10 \mathrm{ml}$ in position 2 (Fig. 1). Four extra commutation valves were included in the module used. For all valves, the exchange options were classified in on/off lines. The 'off' line was assigned to the solution flasks and the 'on' line was reserved for the flow network in the valves placed at the multi-syringe. For the other valves, the positions 'on/off' were chosen to minimise the time during which the valves were switched on in order to avoid overheating problems.

A personal computer, running lab-made software written in QuickBasic 4.5 (Microsoft), controlled the multi-syringe operation (direction of piston movement and position of all commutation valves).

As detection system, a Jenway 6300 (Essex, UK) spectrophotometer equipped with a Hellma (Mullheim/Baden, Germany) 178.712-QS flow-through cell (internal volume $18 \mu \mathrm{l}$ ) was used and the wavelength was set at $510 \mathrm{~nm}$ (determination of iron) or $420 \mathrm{~nm}$ (determination of boron). The analytical signals were recorded in a Kipp and Zonen (Delft, The Netherlands) BD 111 strip chart recorder.

\section{Manifold and MSFIA procedure}

The system components were disposed as shown schematically in Fig. 1. All connections were made of Omnifit (Cambridge, UK) PTFE tubing ( $0.8 \mathrm{~mm}$ i.d.) with Gilson (Villiersle-Bel, France) end-fittings and connectors.

The connections between valves V1/V2 and V5 were $50 \mathrm{~cm}$ long. The connection between valve $\mathrm{V} 3$ and confluence $\mathrm{T}$ had the same length. The tubing length between valve V6 and confluence T was $5 \mathrm{~cm}$. In the manifold developed for determination of iron (Fig. 1A), the connection between valves V4 and V7 was $60 \mathrm{~cm}$ long. The tubing connections

(A)

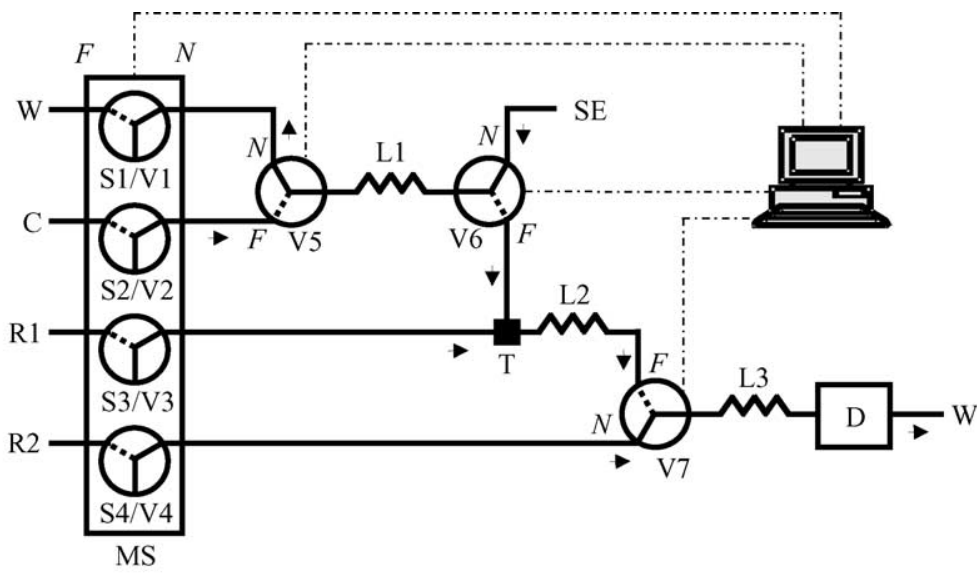

(B)

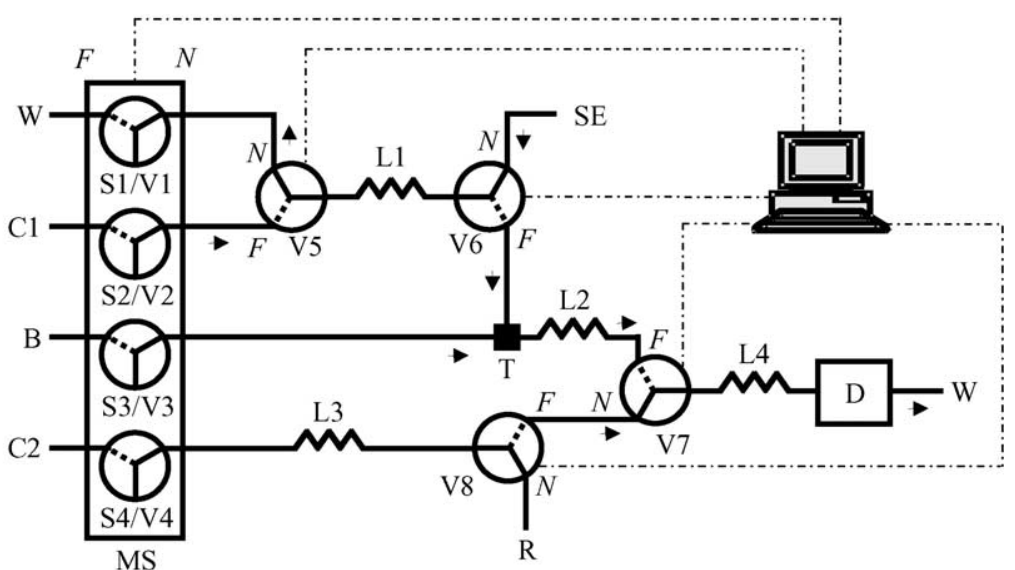

Fig. 1. MSFIA manifolds for the determination of iron (A) and boron (B) in soil extracts: MS, multi-syringe; Si, syringe; Vi, commutation valves; $N$, on position (solid line); F, off position (dotted line); D, detector; T, confluence; Li, PTFE connections; C, C1, water; B, buffer solution; R, azomethine-H reagent; R1, C2, ascorbic acid solution; R2, 1,10-phenanthroline reagent; SE, soil extract/standard solution; W, waste. 
Table 1

Protocol sequence for the determination of iron in soil extracts

\begin{tabular}{|c|c|c|c|c|c|c|c|c|c|}
\hline \multirow[t]{2}{*}{ Description } & \multicolumn{7}{|c|}{ Position of the commutation valves } & \multirow[t]{2}{*}{ Volume $(\mu 1)$} & \multirow[t]{2}{*}{ Time (s) } \\
\hline & 1 & 2 & 3 & 4 & 5 & 6 & 7 & & \\
\hline Syringes are filled and sample is aspirated through L1 & $N$ & $F$ & $F$ & $F$ & $N$ & $N$ & $F$ & 3950 & 15.8 \\
\hline Sample and reducing reagent are sent towards L2 & $F$ & $N$ & $N$ & $F$ & $F$ & $F$ & $F$ & 350 & 7.0 \\
\hline $\begin{array}{l}\text { Sample and colour reagent are sent towards detection } \\
\text { system; reaction product detection }\end{array}$ & $F$ & $N$ & $F$ & $N$ & $F$ & $F$ & $C$ & 2000 & 40.0 \\
\hline The system is washed with carrier & $F$ & $N$ & $F$ & $F$ & $F$ & $F$ & $F$ & 1600 & 19.2 \\
\hline
\end{tabular}

The indicated values for volume refer to syringe $2(10 \mathrm{ml}) . N$ and $F$ represent position on and off, respectively. $C$ represents valve commutation between positions on and off at $7 \mathrm{~Hz}$.

indicated in Fig. 1A as L1 to L3 were 15, 90 and $37 \mathrm{~cm}$ long.

In the manifold developed for determination of boron (Fig. 1B), the connection between valves V7 and V8 was $6 \mathrm{~cm}$ long. The tubing connections designated in Fig. 1B as L1 to L4 were 40, 35, 120 and $200 \mathrm{~cm}$ long.

The protocol sequence adopted for the determination of iron in soil extracts is given in Table 1. The procedure included four steps. The first step consisted of filling L1 tube with standard/sample by aspiration through syringe 1 while the other syringes were also filled with their respective solutions. Next, the sample plug trapped in L1 was pushed by carrier towards the confluence point (Fig. 1A, T), where it was merged with reducing solution propelled by syringe 3 until it reached valve V7. After that, the mixture between sample and reducing agent was propelled further by carrier, passing valve $\mathrm{V} 7$, where colour reagent was added. This addition was performed while valve V7 was commutated between positions 'on' and 'off' at $7 \mathrm{~Hz}$, originating a plug where small segments of the previous solutions were intercalated. During this step, the reaction product was measured in the spectrophotometer. Finally, the tubing portions denoted as L1, L2 and L3 in Fig. 1 were washed with carrier. After this step, the flow system was ready for a new analytical cycle.

In Table 2, the protocol sequence for determination of boron is listed, including five steps. The first step consisted of filling L1 tube with standard/sample by aspiration through syringe 1 while the other syringes were also filled with their respective solutions. Afterwards, $50 \mu \mathrm{l}$ of reagent solution was drawn towards L3. Next, the sample plug trapped in L1 was pushed by carrier towards the confluence point (Fig. 1B,
T), where it was merged with buffer solution propelled by syringe 3 until it reached valve V7. At this point, colour reagent was added to the mixture between sample and buffer solution. This addition was also performed while valve V7 was commutated between positions 'on' and 'off' at $7 \mathrm{~Hz}$, and further propelled towards $\mathrm{L} 4$. Then, the flow was stopped for reaction development. After $60 \mathrm{~s}$, the reaction product was directed to the spectrophotometer, where absorbance was monitored. After this step, the flow system was ready for a new analytical cycle. For determination of blank signal in samples, the aspiration of colour reagent (step 2) was omitted.

\section{Soil extraction procedure}

The soil extracts were used for both reference and MSFIA determinations. Before the extraction procedure, the soil samples were air-dried, ground and sieved.

For the determination of available iron, $25 \mathrm{~g}$ of soil were shaken for $30 \mathrm{~s}$ with $250 \mathrm{ml}$ of $1 \mathrm{moll}^{-1} \mathrm{NH}_{4} \mathrm{CH}_{3} \mathrm{COO}$ solution ( $\mathrm{pH} 3$ ) and, subsequently, vacuum filtered through filter paper. The soil was leached in the filter with three times $50 \mathrm{ml}$ of the extraction solution. Next, the filtrate was evaporated in a sand bath and then treated with $10 \mathrm{ml}$ of aqua regia until dryness for removing traces of organic matter. The residue was taken up with $1 \mathrm{ml}$ of $1 \mathrm{moll}^{-1} \mathrm{HCl}$ to a $100 \mathrm{ml}$ volumetric flask, and the volume was made up with water [15].

The extracts for determination of boron were prepared by weighing $25 \mathrm{~g}$ of soil to a refluxing flask. Next, $50 \mathrm{ml}$ of water were added. This flask was placed on a hot plate equipped with a refluxing apparatus and boiled for $10 \mathrm{~min}$. After cooling, the mixture was vacuum filtered through filter paper and the filtrate was collected [16].

Table 2

Protocol sequence for the determination of boron in soil extracts

\begin{tabular}{|c|c|c|c|c|c|c|c|c|c|c|}
\hline \multirow[t]{2}{*}{ Description } & \multicolumn{8}{|c|}{ Position of the commutation valves } & \multirow[t]{2}{*}{ Volume $(\mu \mathrm{l})$} & \multirow[t]{2}{*}{ Time $(\mathrm{s})$} \\
\hline & 1 & 2 & 3 & 4 & 5 & 6 & 7 & 8 & & \\
\hline Syringes are filled and sample is aspirated through L1 & $N$ & $F$ & $F$ & $F$ & $N$ & $N$ & $F$ & $F$ & 3850 & 15.4 \\
\hline Colour reagent is aspirated through $\mathrm{L} 3^{\mathrm{a}}$ & $F$ & $F$ & $F$ & $N$ & $F$ & $F$ & $F$ & $N$ & 200 & 3.0 \\
\hline Sample, buffer solution and colour reagent are sent towards L4 & $F$ & $N$ & $N$ & $N$ & $F$ & $F$ & $C$ & $F$ & 650 & 19.5 \\
\hline Flow stop for reaction development & $F$ & $F$ & $F$ & $F$ & $F$ & $F$ & $F$ & $F$ & - & 60 \\
\hline Reaction product is sent towards detection system & $F$ & $N$ & $N$ & $N$ & $F$ & $F$ & $C$ & $F$ & 3400 & 102 \\
\hline
\end{tabular}

The indicated values for volume refer to syringe $2(10 \mathrm{ml}) . N$ and $F$ represent position on and off, respectively. $C$ represents valve commutation between positions on and off at $7 \mathrm{~Hz}$.

${ }^{a}$ This step is not performed for measurement of sample blank. 


\section{Reference procedure}

The reference procedure for determination of iron was carried out after the method proposed by Hesse [15] based on the spectrophotometric detection of ferroin complex. For each extract, the determination was performed in triplicate.

For the determination of boron, the reference procedure based on azomethine-H reaction and recommended by the Council on Soil Testing and Plant Analysis was followed [16]. For each extract, the determination was performed in triplicate. Sample blank measurements were also performed in triplicate whenever necessary by replacing the azomethine$\mathrm{H}$ reagent by $20 \mathrm{~g}^{-1}$ ascorbic acid solution.

\section{Results and discussion}

\section{Determination of iron in soil extracts by MSFIA}

The first goal of this work was to develop a multi-syringe flow system enabling the determination of available iron using spectrophotometric detection. Hence, a multi-syringe flow system was devised to allow the reaction of $\mathrm{Fe}$ (II) with 1,10-phenanthroline in a buffered media, after reduction of $\mathrm{Fe}(\mathrm{III})$ to $\mathrm{Fe}(\mathrm{II})$ in acidic media [17].

In multi-syringe flow systems it is not feasible to introduce the sample into the system through one of the available syringes, as it would take a long time of washing steps to avoid carry-over between consecutive samples. Hence, other devices (selection or commutation valves) must be incorporated to the manifold to provide access to these solutions. Therefore, valves V5 and V6 were included in the present manifold. The tubing connecting these two valves (Fig. 1A, L1) defined the volume of sample to be introduced into the flow system. Moreover, the tubing L2 (Fig. 1A) was placed in the flow manifold to allow previous reduction of Fe(III) to $\mathrm{Fe}(\mathrm{II})$ prior to the colour reaction.

For this application, syringes with different capacities were applied. A larger syringe $(10 \mathrm{ml})$ was chosen for the carrier stream when compared to those chosen for the reducing reagent $(5 \mathrm{ml})$ and for the colour reagent $(2.5 \mathrm{ml})$. These volumes were chosen in order to minimise sample dilution when these reagents were added to sample in confluence $\mathrm{T}$ and valve $\mathrm{V} 7$, respectively.

To avoid Schlieren effect reported previously [18], the addition of colour reagent to the sample was performed through a commutation valve (V7), which alternated between the two streams, providing the intercalation of small segments of those solutions. This approach aimed the improvement of the mixture conditions, minimising the gradient of refractive index within the flow cell.

The flow rate values were fixed at 15.0, 3.0, 3.0 and $5.0 \mathrm{ml} \mathrm{min}^{-1}$ for steps $1-4$ in the analytical cycle (Table 1) and the time required for washing and filling steps was minimised. Moreover, the fourth step was introduced to reduce reagent consumption by using the carrier (water) to wash the flow cell and channels before a new determination cycle.

The influence of some chemical variables in the performance of the flow system was studied by establishing calibration curves between 0.50 and $10.0 \mathrm{mg} \mathrm{Fe}^{-1}$. The univariate method was chosen, where the value of one parameter was varied while the others were kept constant.

First, the ascorbic acid concentration was studied in order to assure the complete reduction of $\mathrm{Fe}$ (III) to $\mathrm{Fe}$ (II) for the highest concentration of iron present in the calibration curve $\left(10 \mathrm{mgl}^{-1}\right)$. This study was performed using $150 \mu \mathrm{l}$ as sample volume and a colour reagent solution containing 1,10-phenanthroline $0.40 \mathrm{gl}^{-1}, \mathrm{NaOH} 0.6 \mathrm{moll}^{-1}$ and $\mathrm{NaCH}_{3} \mathrm{COO} 2 \mathrm{moll}^{-1}$. Solutions containing between 0.010 and $7.5 \mathrm{gl}^{-1}$ of ascorbic acid in $0.3 \mathrm{moll}^{-1}$ of $\mathrm{HCl}$ were tested. $\mathrm{Fe}$ (II) and $\mathrm{Fe}$ (III) standards containing $0.2 \mathrm{moll}^{-1}$ of $\mathrm{HCl}$ were injected and $2.5 \mathrm{~g}^{-1}$ was found to be the minimum concentration of ascorbic acid to provide equal peak heights, indicating complete reduction of $\mathrm{Fe}(\mathrm{III})$ to $\mathrm{Fe}(\mathrm{II})$. Nevertheless, a higher concentration $\left(5.0 \mathrm{~g}^{-1}\right)$ was chosen for further studies to guarantee that any interference from the soil extract matrix was avoided.

The concentration of 1,10-phenanthroline in the colour reagent solution was also studied, using the same conditions described above. Concentration values between 0.10 and $0.70 \mathrm{gl}^{-1}$ were tested. For the $0.10 \mathrm{gl}^{-1}$ solution, absorbance values increased for $\mathrm{Fe}$ (II) standards containing up to $4 \mathrm{mg} \mathrm{l}^{-1}$. Above this value, absorbance values were the same for all iron solutions. For the other concentration values of 1,10-phenanthroline, similar linear calibration curves were obtained for the $\mathrm{Fe}$ (II) standards tested. Hence, the lowest concentration of this group $\left(0.25 \mathrm{gl}^{-1}\right)$ was chosen for further studies.

As a wide range of acidity values $\left(0.3-0.9 \mathrm{moll}^{-1}\right)$ was previously observed for this type of soil extracts, standards containing $0.9 \mathrm{moll}^{-1}$ of $\mathrm{HCl}$ were also analised using the conditions stated above. The calibration curve obtained presented higher values for both slope and intercept when compared to that provided by standards with $0.2 \mathrm{moll}^{-1} \mathrm{HCl}$ (Table 3; $\mathrm{NaOH}=0.6 \mathrm{moll}^{-1}$ ). This situation was probably due to an excess of $\mathrm{NaOH}$ in the reagent solution when the solutions of lower acidity were used, which resulted in an alkaline $\mathrm{pH}$ value. This was confirmed by collecting a few drops from the waste tube in a $\mathrm{pH}$ universal indicator paper, a few seconds after the peak appearance. For the lower acidity standards, the $\mathrm{pH}$ was above 12 , while for the higher acidity standards it was about 4 . Therefore, the concentration of $\mathrm{NaOH}$ in the reagent solution was varied between 0.2 and $0.8 \mathrm{moll}^{-1}$ in order to find a concentration value that could provide similar results for standards containing either 0.2 or $0.9 \mathrm{moll}^{-1}$ of $\mathrm{HCl}$. The parameters obtained for the calibration curves are presented in Table 3. For the lower acidity standards, higher slope values were observed for lower concentrations of $\mathrm{NaOH}$. This situation was reversed for the higher acidity standards and it was not possible to obtain similar calibration curves for the dif- 
Table 3

Slope and intercept values from calibration curves established using different concentrations of $\mathrm{NaOH}$ in the colour reagent for Fe(II) standards between 0.5 and $10.0 \mathrm{mg} \mathrm{l}^{-1}$, containing either $0.2 \mathrm{moll}^{-1}$ (calibration A) or $0.9 \mathrm{~mol}^{-1}$ (calibration B) of $\mathrm{HCl}$

\begin{tabular}{|c|c|c|c|c|}
\hline \multirow[t]{2}{*}{ Concentration of $\mathrm{NaOH}\left(\mathrm{moll}^{-1}\right)$} & \multicolumn{2}{|l|}{ Calibration A } & \multicolumn{2}{|l|}{ Calibration B } \\
\hline & Slope (AU mg $\left.{ }^{-1} 1\right)$ & Intercept (AU) & Slope $\left(\mathrm{AU} \mathrm{mg}^{-1} \mathrm{l}\right)$ & Intercept (AU) \\
\hline 0.2 & $0.0603 \pm 0.0005$ & $0.056 \pm 0.003$ & $0.0523 \pm 0.0006$ & $0.079 \pm 0.004$ \\
\hline 0.4 & $0.0600 \pm 0.0005$ & $0.057 \pm 0.003$ & $0.0552 \pm 0.0006$ & $0.074 \pm 0.004$ \\
\hline 0.5 & $0.0598 \pm 0.0002$ & $0.051 \pm 0.001$ & $0.0567 \pm 0.0002$ & $0.073 \pm 0.002$ \\
\hline 0.6 & $0.0564 \pm 0.0002$ & $0.054 \pm 0.001$ & $0.0590 \pm 0.0004$ & $0.075 \pm 0.002$ \\
\hline 0.8 & $0.0444 \pm 0.0005$ & $0.051 \pm 0.003$ & $0.0599 \pm 0.0004$ & $0.071 \pm 0.002$ \\
\hline
\end{tabular}

$R>0.998$ for all calibration curves. AU = absorbance units.

ferent acidity values using the $\mathrm{NaOH}$ concentration values tested.

Therefore, $\mathrm{NaOH}$ was removed from the reagent solution but the buffer capacity could not be increased as a high concentration of $\mathrm{NaCH}_{3} \mathrm{COO}$ was already applied $\left(2 \mathrm{moll}^{-1}\right)$. Hence, the sample injection volume was lowered in order to increase sample dispersion inside the flow system. For an injection value of $100 \mu l$, the sensitivity obtained when using $\mathrm{Fe}$ (II) standards containing $0.9 \mathrm{~mol}^{-1}$ of $\mathrm{HCl}$ was about $90 \%$ of that obtained for standards containing $0.2 \mathrm{moll}^{-1}$. Nevertheless, similar calibration curves were obtained for both acidity values when 50 or $75 \mu \mathrm{l}$ of sample were injected. The chosen value was $75 \mu \mathrm{l}$ as it provided better sensitivity than $50 \mu l$.

As extracts were prepared in about $400 \mathrm{ml}$ of $\mathrm{NH}_{4} \mathrm{CH}_{3} \mathrm{COO}, 1 \mathrm{moll}^{-1}$ that was dried and then re-dissolved in $100 \mathrm{ml}$, the solutions to be analysed had a high salt content. Therefore, the influence of ionic strength in the colour reaction was evaluated through calibration curves obtained using standards containing $0.2 \mathrm{moll}^{-1} \mathrm{HCl}$ and $\mathrm{NaCl}$ up to $4.5 \mathrm{~mol}^{-1}$. The values of slope obtained for standards without $\mathrm{NaCl}$ or with 2 or $4 \mathrm{moll}^{-1}$ of this reagent were $89.0,92.6$ and $95.2 \%$ of the value obtained when standards with $4.5 \mathrm{~mol} \mathrm{l}^{-1}$ of $\mathrm{NaCl}$ were used. The difference for the intercept values was higher as these values were 42.1, 69.4 and $76.8 \%$ of that obtained for the highest concentration of $\mathrm{NaCl}$. These results indicated that this parameter could affect the accuracy of this determination. Hence, the chosen concentration was $4 \mathrm{moll}^{-1}$ of $\mathrm{NaCl}$ as it was the closest value to the approximate ionic strength of the soil extracts.

The interference of other ions in the determination of iron was investigated; tolerance limits were taken as the largest amount yielding errors less than $5 \%$ when $\mathrm{Fe}$ (II) concentration value was determined. The tolerance limit for $\mathrm{Zn}$ (II) and $\mathrm{Cu}$ (II) was $20 \mathrm{mg} \mathrm{l}^{-1}$ while for $\mathrm{Al}(\mathrm{III}), \mathrm{Mn}$ (II) and $\mathrm{Ca}(\mathrm{II})$ no interference was detected up to $1000 \mathrm{mg}^{-1}$ in the presence of $2.0 \mathrm{mg} \mathrm{Fe}^{-1}$.

\section{Determination o fboron in soil extracts by MSFIA}

The second objective of this work was to develop a multisyringe flow injection system for determination of boron in soil extracts resorting to the azomethine-H reaction [17]. Ini- tially, it was intended to use a manifold configuration similar to that established for the determination of iron, maintaining water as carrier (syringe 2) and replacing the ascorbic acid solution by buffer solution (syringe 3), and also the phenanthroline solution by azomethine-H solution (syringe 4). Nevertheless, the hot water soil extracts presented a yellowish colour, resulting in absorption of radiation in the same wavelength of detection. To overcome this problem, the manifold must also accommodate the possibility of performing in-line measurement of sample blank. Hence, the azomethine- $\mathrm{H}$ solution was removed from syringe 4 and valve V8 was placed in the manifold to allow introduction of colour reagent in L3 whenever the determination was aimed. When the sample blank signal was intended, this operation was omitted.

Using the manifold depicted in Fig. 1B, the flow rates were fixed at 15.0, 4.0, 2.0 and $2.0 \mathrm{ml} \mathrm{min}^{-1}$ for steps $1-3$ and 5 of the analytical cycle (Table 2 ) and the influence of some variables in the performance of the flow system was studied. The composition of buffer solution was not changed, excepted for its $\mathrm{pH}$. The reagent volume was also kept constant at $50 \mu \mathrm{l}$.

First, the concentration of azomethine- $\mathrm{H}$ was studied between 6 and $15 \mathrm{gl}^{-1}$. This study was performed using $200 \mu \mathrm{l}$ as sample volume, $\mathrm{pH}$ buffer at 7.5 and a stop period of $1 \mathrm{~min}$ before detection of analytical signal. When standard solutions between 0.20 and $2.40 \mathrm{mg} \mathrm{l}^{-1}$ were injected, both blank signal (intercept) and sensitivity (slope) increased when the azomethine-H concentration was increased. Despite the high value of intercept (about 0.360 absorbance units), the concentration chosen was $15 \mathrm{gl}^{-1}$ as lower values provided poor sensitivity. For the lowest concentration of azomethine-H $\left(6 \mathrm{~g}^{-1}\right)$ it was not possible to distinguish between the blank signal and the lowest standard $\left(0.20 \mathrm{mg}^{-1}\right)$.

Next, the influence of $\mathrm{pH}$ value in buffer solution was studied. Using the same conditions stated above, the $\mathrm{pH}$ was varied between 6.4 and 8.0 and standards between 0.20 and $4.00 \mathrm{mg}^{-1}$ were analysed. For a $\mathrm{pH}$ value of 8.0 , the blank absorbance value was higher than 1.00 . Hence, no calibration curve was established for this solution. Similar sensitivity values were obtained for $\mathrm{pH}$ values between 6.8 and 7.6, but the intercept value was about 60 and $90 \%$ for $\mathrm{pH}$ values of 6.8 and 7.2 when compared to the value provided by the solution of 7.6. Therefore, the $\mathrm{pH}$ value chosen for further studies was 6.8 . 


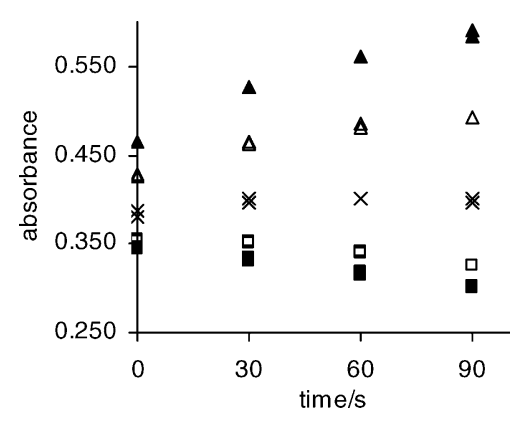

Fig. 2. Results obtained for different time intervals of flow stop before reaction product detection in the determination of boron. The following boron standards $\left(\mathrm{mg} \mathrm{l}^{-1}\right)$ are represented: $\square(0), \square(0.20), \times(0.80), \triangle(1.60)$ and $\Delta(2.40)$.

The importance of sample volume was evaluated between 100 and $300 \mu \mathrm{l}$, using the previous conditions. The values of intercept were similar while the sensitivity increased with increasing sample volumes. Compared to the value obtained for $300 \mu \mathrm{l}$, the sensitivity for 200 and $250 \mu \mathrm{l}$ were about $90 \%$ of that value while for 150 and $100 \mu$, it represented about 65 and $46 \%$ of that value, respectively. Hence the value chosen for further determinations was $200 \mu \mathrm{l}$ in order to minimise the blank signal from intrinsic absorbance of sample without compromising the sensitivity attained.

Using the above conditions, the sensitivity obtained was low for the concentration range aimed $\left(0.5-2.5 \mathrm{mgl}^{-1}\right)$, which is adequate for normal plant growth [16]. Hence, further investigation on the azomethine- $\mathrm{H}$ concentration was carried out. In this experiment, azomethine-H concentrations between 15 and $24 \mathrm{~g}^{-1}$ were tested. As verified before, an increase of both slope and intercept was verified as the concentration of azomethine-H was raised. When compared to the $15 \mathrm{~g}^{-1}$ solution, both values increased about 1.2 and 1.6 times for the solutions containing 18 and $21 \mathrm{~g} \mathrm{l}^{-1}$, respectively. For the solution containing $24 \mathrm{gl}^{-1}$, the slope was increased about 1.7 times while the intercept value was about twice that obtained for the $15 \mathrm{~g}^{-1}$ solution. Therefore, as a compromise between enhancement of sensitivity and lower of intercept value, the chosen concentration was $21 \mathrm{~g} \mathrm{l}^{-1}$

Finally, the necessity of a flow stop period for reaction development was evaluated by omitting or modifying the time during which step 4 took place $(30,60$ or $90 \mathrm{~s})$. The results obtained are presented in Fig. 2. Lower blank signals and higher sensitivity were obtained when the reaction time was increased. Nevertheless, the time chosen for further determinations was $60 \mathrm{~s}$ to avoid compromising the determination frequency.

It was noticed that different calibration curves were obtained when the azomethine-H solution was prepared and used immediately. To evaluate the reagent stability, several consecutive calibration curves were obtained using standards between 0.20 and $2.40 \mathrm{mg} \mathrm{l}^{-1}$. After $1 \mathrm{~h}$ from preparation, the value of slope decreased $5 \%$ while the intercept decreased $10 \%$. During the subsequent $3 \mathrm{~h}$, no alteration was observed. After $24 \mathrm{~h}$, the calibration curve was maintained. Hence, it is recommended to wait at least $1 \mathrm{~h}$ after the preparation of the reagent solution prior to its introduction into the flow system.

The interference of other species in the determination of boron was also investigated; tolerance limits were taken as the largest amount yielding errors less than 5\% when boron concentration value was determined. For a boron solution containing $1.0 \mathrm{mg} \mathrm{B}^{-1}$, the tolerance limit for $\mathrm{Al}$ (III) and $\mathrm{Cu}$ (II) was $100 \mathrm{mg}^{-1}$ while for $\mathrm{Fe}(\mathrm{III})$ and $\mathrm{Mo}$ (VI) it was $50 \mathrm{mg} \mathrm{l}^{-1}$. The lowest value was obtained for $\mathrm{Cr}(\mathrm{VI})$, which gave a tolerance limit of $10 \mathrm{mg}^{-1}$.

\section{Application to soil extracts}

The figures of merit obtained for both determinations are summarised in Table 4. A linear response between absorbance and concentration was obtained over the range of $0.50-10.0 \mathrm{mg} \mathrm{Fe}^{-1}$ and $0.20-4.0 \mathrm{mg} \mathrm{B}^{-1}$.

To estimate the determination frequency, the time required for data transference between the computer and the multisyringe must also be accounted, besides the time taken for each step of the analytical cycle. Hence, the whole procedure took $105 \mathrm{~s}$ for the determination of iron and $230 \mathrm{~s}$ for the determination of boron, providing determination rate values of 34 and $15 \mathrm{~h}^{-1}$, respectively.

The detection limit was calculated as the concentration corresponding to the blank signal plus three times the S.D. of 10 consecutive blank injections [19]. The blank signal was obtained by injecting solutions with the same composition as the standards, except for iron or boron. For the proposed methodologies, the calculated detection limits were $0.27 \mathrm{mg} \mathrm{Fe}^{-1}$ and $0.05 \mathrm{mg} \mathrm{B}^{-1}$.

For the determination of iron, the repeatability of the system was assessed from five consecutive determinations of each soil extract, containing concentrations of iron between

Figures of merit of the proposed MSFIA methodologies

\begin{tabular}{lll}
\hline & Determination of iron & Determination of boron \\
\hline Concentration interval $\left(\mathrm{mg} \mathrm{l}^{-1}\right)$ & $0.50-10.0$ & $0.20-4.0$ \\
Detection limit $\left(\mathrm{mg} \mathrm{l}^{-1}\right)$ & 0.27 & 34 \\
Determination frequency $\left(\mathrm{h}^{-1}\right)$ & $<2.0 \%$ & 15 \\
Repeatability $(n=5)$ & 5.62 & 8.10 \\
Effluent produced per determination $(\mathrm{ml})$ & $1.4 \%$ \\
\hline
\end{tabular}


Table 5

Results $\left(\mathrm{mg}^{-1}\right)$ obtained by MSFIA methodology $\left(C_{\text {MSFIA }}\right)$ and by the reference procedure $\left(C_{\mathrm{RP}}\right)$ for the determination of iron and boron in soil extracts

\begin{tabular}{|c|c|c|c|c|c|c|}
\hline \multirow[t]{2}{*}{ Samples } & \multicolumn{3}{|l|}{ Iron } & \multicolumn{3}{|l|}{ Boron } \\
\hline & $C_{\text {MSFIA }}$ & $C_{\mathrm{RP}}$ & R.D. (\%) & $C_{\text {MSFIA }}$ & $C_{\mathrm{RP}}$ & R.D. (\%) \\
\hline A & $3.44 \pm 0.02$ & $3.41 \pm 0.04$ & 0.9 & $0.22 \pm 0.02$ & $0.23 \pm 0.03$ & -4.3 \\
\hline B & $3.12 \pm 0.02$ & $3.14 \pm 0.03$ & -0.6 & $0.37 \pm 0.03$ & $0.39 \pm 0.01$ & -5.1 \\
\hline $\mathrm{C}$ & $4.89 \pm 0.03$ & $4.94 \pm 0.03$ & -1.0 & $0.28 \pm 0.04$ & $0.27 \pm 0.01$ & 3.7 \\
\hline $\mathrm{D}$ & $1.77 \pm 0.02$ & $1.78 \pm 0.04$ & -0.6 & $1.19 \pm 0.02$ & $1.17 \pm 0.01$ & 1.7 \\
\hline $\mathrm{E}$ & $1.58 \pm 0.02$ & $1.60 \pm 0.06$ & -1.3 & $2.09 \pm 0.02$ & $2.10 \pm 0.02$ & -0.5 \\
\hline $\mathrm{F}$ & $4.42 \pm 0.01$ & $4.40 \pm 0.06$ & 0.5 & $1.78 \pm 0.03$ & $1.81 \pm 0.03$ & -1.7 \\
\hline G & $1.51 \pm 0.03$ & $1.49 \pm 0.01$ & 1.3 & - & - & - \\
\hline $\mathrm{H}$ & $4.28 \pm 0.01$ & $4.29 \pm 0.03$ & -0.2 & - & - & - \\
\hline
\end{tabular}

1.51 and $4.89 \mathrm{mg}^{-1}$. The R.S.D. values varied between 0.6 and $2.0 \%$. For the determination of boron, the repeatability of this system was assessed from 10 consecutive injections of $0.80 \mathrm{mg} \mathrm{l}^{-1}$ standard solution, providing the value of $1.4 \%$.

The proposed systems were applied to the determination of iron and boron in several soil extracts. The results $\left(C_{\text {MSFIA }}\right)$ were compared with those furnished by the reference procedure $\left(C_{\mathrm{RP}}\right)$ and are presented in Table 5.

For comparison purposes, a linear relationship $\left(C_{\mathrm{MSFIA}}=\right.$ $C_{0}+S C_{\mathrm{RP}}$ ) was established. The equation found for the determination of iron was $C_{\mathrm{MSFIA}}=0.008( \pm 0.066)+0.996$ $( \pm 0.020) C_{\mathrm{RP}}$ while for the determination of boron the equation was $C_{\text {MSFIA }}=-0.001( \pm 0.038)+0.994( \pm 0.030) C_{\mathrm{RP}}$. For both equations, the values in parenthesis are the limits of the $95 \%$ confidence intervals and $R=0.9998$. From these figures, it is clear that the calculated slope and intercept do not differ significantly from the values 1 and 0 , respectively. Hence, there is no evidence for systematic differences between the two sets of results [20] obtained by the proposed methodology and the reference procedure, for both determinations.

\section{Conclusions}

In the present work, multi-syringe flow injection systems were devised and applied to soil analysis, providing reliable results for the spectrophotometric determination of available iron and boron in this matrix. Soil extracts were introduced directly into the flow system, where $\mathrm{pH}$ adjustment was carried out in-line.

In the determination of iron, problems due to differences in the refractive index of solutions (Schlieren effect) flowing inside the system were avoided by taking advantage of the binary approach. The application of this strategy to enhance mixing conditions was possible through fast and precise change between reagent and sample streams by commutation of one of the valves present in the flow system.

In the determination of boron, the configuration proposed allowed the measurement of sample blank through computer control, without physical reconfiguration or solution exchange. In this case, the analytical path and the sample dilution were the same as in the determination cycle by omitting the step concerning the azomethine-H reagent introduction. Moreover, no interference or contamination from the borosilicate glass syringe was noticed, probably because the configuration proposed avoided its direct contact.

In the present moment, other MSFIA systems for soil analysis are under development, resorting to the same type of instrumentation. The determination of other species present in soil is aimed by using suitable reagents and through modification of parameter values in the controlling software, in order to provide a flexible tool for assessment of micronutrient status in soil samples.

\section{Acknowledgement}

The authors thank IFADAP for financial support through project AGRO 273.

\section{References}

[1] J. Ruzicka, E.H. Hansen, Anal. Chim. Acta 78 (1975) 145.

[2] L.T. Skegg, Am. J. Clin. Pathol. 28 (1957) 311.

[3] J. Ruzicka, E.H. Hansen, Flow Injection Analysis, 2nd ed., Wiley, New York, 1988.

[4] E.H. Hansen, Anal. Chim. Acta 308 (1995) 3.

[5] J. Ruzicka, G.D. Marshall, Anal. Chim. Acta 237 (1990) 329.

[6] J. Ruzicka, Anal. Chim. Acta 261 (1992) 3.

[7] J. Wang, E.H. Hansen, Trac-Trend. Anal. Chem. 22 (2003) 225

[8] J. Ruzicka, Analyst 125 (2000) 1053.

[9] E.A.G. Zagatto, B.F. Reis, C.C. Oliveira, R.P. Sartini, M.A.Z. Arruda, Anal. Chim. Acta 400 (1999) 249.

[10] B.F. Reis, M.F. Giné, E.A.G. Zagatto, J.L.F.C. Lima, R.A. Lapa, Anal. Chim. Acta 293 (1994) 129.

[11] F.R.P. Rocha, B.F. Reis, E.A.G. Zagatto, J.L.F.C. Lima, R.A.S. Lapa, J.L.M. Santos, Anal. Chim. Acta 468 (2002) 119.

[12] V. Cerdà, J.M. Estela, R. Forteza, A. Cladera, E. Becerra, P. Altimira, P. Sitjar, Talanta 50 (1999) 695.

[13] M. Miró, V. Cerdà, J.M. Estela, Trac-Trend. Anal. Chem. 21 (2002) 199.

[14] V. Cerdà, J. Flow Injection Anal. 20 (2003) 203.

[15] P.R. Hesse, A Textbook of Soil Chemical Analysis, Chemical Publishing Co., New York, 1972, pp. 332-340, 353-355.

[16] Soil and Plant Analysis Council, Handbook on Reference Methods for Soil Analysis, Soil and Plant Analysis Council, Athens, GA, 1992, pp. 129-132. 
[17] Z. Marczenko, M. Balcerzak, Separation Preconcentration and Spectrophotometry in Inorganic Analysis, Elsevier Science B.V., Amsterdam, 2000, pp. 125-126/228-229.

[18] A.M.R. Ferreira, J.L.F.C. Lima, A.O.S.S. Rangel, Analusis 29 (1998) 327.
[19] IUPAC - International Union of Pure and Applied Chemistry, Anal. Chem. 48 (1976) 2294

[20] J.C. Miller, J.N. Miller, Statistics for Analytical Chemistry, 3rd ed., Ellis Horwood, Chichester, 1993, pp. 120-124. 